\title{
Simulating CMUT Arrays Using Time Domain FEA
}

Engholm, Mathias; Tweedie, Andrew ; Jensen, Jonas; Harvey, Gerald; Diederichsen, Søren Elmin; Jensen, Jørgen Arendt; Thomsen, Erik Vilain

Published in:

2017 IEEE International Ultrasonics Symposium (IUS)

Link to article, DOI:

10.1109/ULTSYM.2017.8092395

Publication date:

2017

Document Version

Peer reviewed version

Link back to DTU Orbit

Citation (APA):

Engholm, M., Tweedie, A., Jensen, J., Harvey, G., Diederichsen, S. E., Jensen, J. A., \& Thomsen, E. V. (2017). Simulating CMUT Arrays Using Time Domain FEA. In 2017 IEEE International Ultrasonics Symposium (IUS) IEEE. https://doi.org/10.1109/ULTSYM.2017.8092395

\section{General rights}

Copyright and moral rights for the publications made accessible in the public portal are retained by the authors and/or other copyright owners and it is a condition of accessing publications that users recognise and abide by the legal requirements associated with these rights.

- Users may download and print one copy of any publication from the public portal for the purpose of private study or research.

- You may not further distribute the material or use it for any profit-making activity or commercial gain

- You may freely distribute the URL identifying the publication in the public portal 


\title{
Simulating CMUT Arrays Using Time Domain FEA
}

\author{
Mathias Engholm*, Andrew Tweedie ${ }^{\dagger}$, Jonas Jensen*, Gerald Harvey ${ }^{\ddagger}$, Søren Elmin Diederichsen*, \\ Jørgen Arendt Jensen ${ }^{\S}$, and Erik Vilain Thomsen* \\ *Department of Micro and Nanotechnology, Technical University of Denmark, DK-2800 Kgs. Lyngby, Denmark \\ ${ }^{\dagger}$ PZFlex, Glasgow, United Kingdom \\ ${ }_{\ddagger}^{\ddagger}$ PZFlex, Cupertino, USA \\ $\S$ Center for Fast Ultrasound Imaging, Department of Electrical Engineering, Technical University of Denmark, \\ DK-2800 Kgs. Lyngby, Denmark
}

\begin{abstract}
PZFlex is a commercial FEA software that has been optimized for the ultrasound industry and is commonly used to design piezoelectric ultrasound transducers. However, PZFlex is not commonly used within the CMUT research field. Nevertheless, it has an explicit modeling approach allowing large structures like CMUT arrays to be modeled and its transient analysis intrinsically supplies non-linear and broadband results from a single run. A 3-D model of a CMUT array is developed with multiple cells in each element and one active element surrounded by $N$ passive elements. It is demonstrated that the electro-mechanics can precisely be predicted, within $3 \%$, including the pull-in voltage and the spring softening effect. The transmit impulse response is simulated by deconvolving the extrapolated pressure with the excitation pulse, and it is in excellent agreement with the measured. It is shown that the impulse response can directly be used in Field II to assess the image quality of the transducer using the lateral, axial and cystic resolution for two different CMUT designs.
\end{abstract}

\section{INTRODUCTION}

Finite element analysis (FEA) has been extensively used for analyzing both static and dynamic behavior of capacitive micromachined ultrasonic transducers (CMUTs) [1], [2]. Typical parameters being evaluated include the pull-in voltage, pressure, sensitivity, bandwidth, and crosstalk. PZFlex is a commercial FEA software, has been optimized for the ultrasound industry and is commonly used to design piezoelectric ultrasound transducers. However, PZFlex is not commonly used within the CMUT research field. Nevertheless, it has an explicit modeling approach allowing large structures like CMUT arrays to be modeled and its transient analysis intrinsically supplies non-linear and broadband results from a single run. Another advantage is that the time domain response calculated in PZFlex can be used directly in the ultrasound simulation program Field II. This gives the possibility of not only evaluating the transducer design on the pressure, receive sensitivity, bandwidth and so on, but it is also possible to simulate an imaging setup and evaluate the image quality in terms of lateral, axial, and cystic resolution.

Only a few papers have been published where PZFlex have been used to simulate CMUTs, and it has mainly been used to investigate element crosstalk [3].

The main objective of this paper is to present a multielement CMUT array model with multiple cells per element developed in PZFlex, and verify the model by comparing the output results to measurements. The second objective is to
TABLE I

MATERIAL PARAMETERS

\begin{tabular}{l|ccc}
\hline \hline Material & $\begin{array}{c}\text { Density } \\
{\left[\mathrm{g} / \mathrm{cm}^{3}\right]}\end{array}$ & $\begin{array}{c}\text { Long. Vel. } \\
{[\mathrm{mm} / \mu \mathrm{s}]}\end{array}$ & $\begin{array}{c}\text { Shear Vel. } \\
{[\mathrm{mm} / \mu \mathrm{s}]}\end{array}$ \\
\hline Silicon & 2.33 & 8.11 & 5.20 \\
Silicon oxide & 2.20 & 5.97 & 3.76 \\
Aluminum & 2.70 & 6.42 & 3.04 \\
RTV Silicone & 1.27 & 1.00 & - \\
Water & 1.00 & 1.50 & - \\
\hline
\end{tabular}

show that the results can directly be used in Field II to evaluate the imaging performance of the transducer.

\section{Methods}

\section{A. PZFlex Models}

1) Single Cell Model: A single CMUT cell is modeled using axial symmetry. The cell consists of a bottom silicon substrate, a silicon oxide layer with a cavity and a silicon plate with an aluminum layer on top. The model is based on the wafer-bonding technique [4]. The substrate and the edges of the model are fixed, and the top is free to move. The top of the substrate acts as the ground electrode and the bottom of the silicon plate acts as the drive electrode. The properties of the materials used are listed in Table I.

2) Linear Array Model: The linear array model consists of a central driven active element, surrounded by $N$ passive elements, with each element containing multiple individual circular CMUT cells placed in a hexagonal grid. Fig. 1 shows a cross section of the model through the plane with the cavities. This model has three cells in each element and the active element is surrounded by three passive elements on each side. The colors of the cells represent which element the cells are placed in. Symmetry is applied along the elevation direction and at the center of the active element, this significantly reduces the model runtime, while allowing crosstalk to be observed across multiple adjacent elements. Fig. 2 shows the full model with the substrate below the CMUTs, an acoustic window on top of the CMUTs made of a Room Temperature Vulcanization (RTV) silicone polymer and water on top. The bottom of the substrate is fixed, and the RTV silicone and the water have an absorbing boundary condition at the boundary where symmetry is not applied. The simulation does not take 


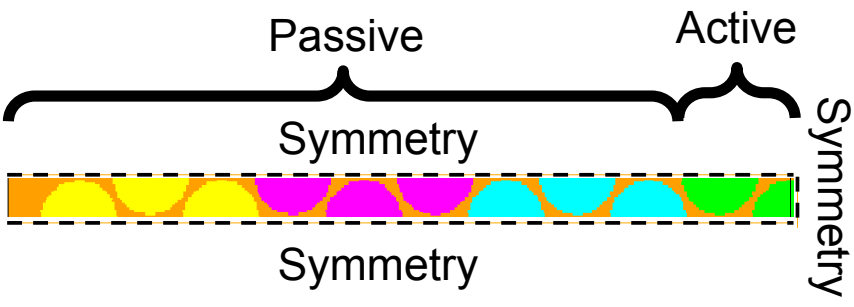

Fig. 1. Cross section of the model through the plane with the cavities. This model has three cells in each element and the active element is surrounded by three elements on each side. The cells are colored in different colors depending on which element they are placed in.

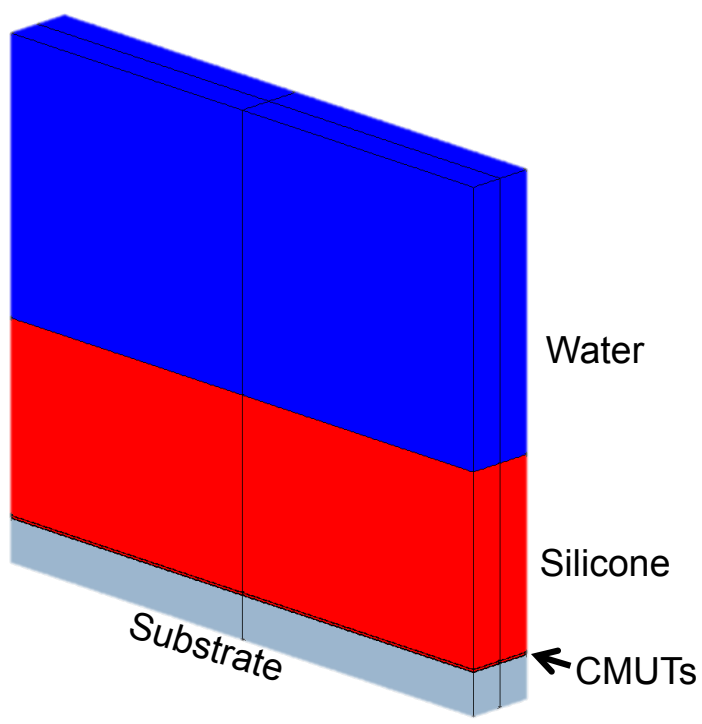

Fig. 2. The full model with the substrate below the CMUTs, an acoustic window on top of the CMUTs of an RTV silicone polymer, and water on top.

any elevation focusing of the RTV lens into account. The transmit electrodes are contacted through a $50 \Omega$ resistor.

The simulation is divided into two stages: first, the bias is applied and second, the voltage or pressure is applied. The biasing stage uses the dynamic relaxation option in PZFlex and increases the voltage gradually until the bias voltage is reached. This option overdamps the mechanical elements so a steady bias state is reached faster. In a future release, a static solver will be implemented to calculate the biasing stage.

\section{B. CMUT probe}

A 192 element linear CMUT array is fabricated and assembled in a probe handle similar to the probe described in [5]. The individual CMUT cells are circular with a radius of $60 \mu \mathrm{m}$ and fabricated using a LOCOS process [6]. The plate thickness is $10 \mu \mathrm{m}$ silicon with $400 \mathrm{~nm}$ aluminum on top. The insulation oxide is $409 \mathrm{~nm}$, the LOCOS nitride is $100 \mathrm{~nm}$, and the vacuum gap is $167 \mathrm{~nm}$. The cells are placed in a hexagonal grid with three cells in each element in the azimuthal direction. The pull-in voltage is $215 \mathrm{~V}$. The acoustic performance of the probe is compared to the PZFlex model.

A second CMUT array has been fabricated with a $2 \mu \mathrm{m}$ plate, a radius of $24.5 \mu \mathrm{m}$ and a pull-in voltage of $240 \mathrm{~V}$. This array is not assembled to a final probe, but only tested using

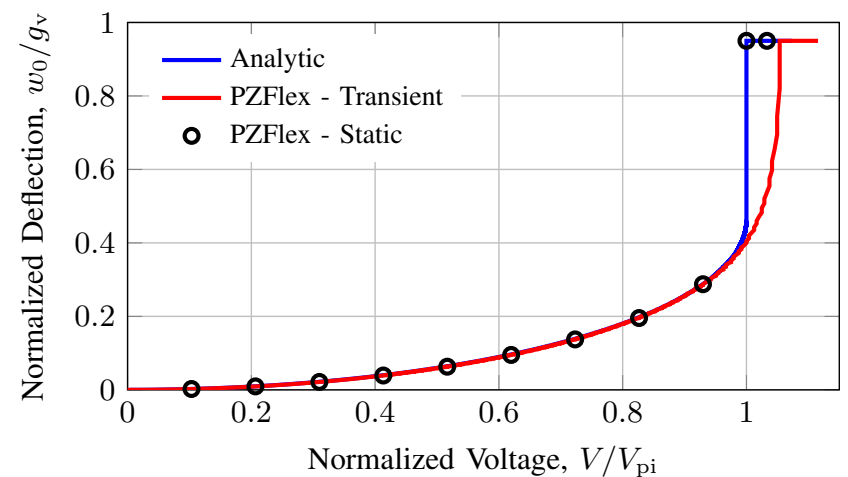

Fig. 3. The normalized deflection shown as function of bias voltage normalized to the pull-in voltage.

an impedance analyzer for evaluating the electro-mechanic performance of the PZFlex model.

\section{Electro-Mechanics}

Two parameters are evaluated to verify that the electromechanical part works: the pull-in voltage and the spring softening effect.

The pull-in voltage, $V_{\mathrm{pi}}$, is defined as the point when the plate snaps down onto the bottom of the cavity. This occurs when the electrostatic force for the applied voltage exceeds the elastic force originating from the plate. The effective spring constant becomes zero when this happens. The stable position of the CMUT can by found by balancing all the forces acting on the plate, and the pull-in voltage can then be derived [7]

$$
V_{\mathrm{pi}}=\sqrt{\frac{89.4459 D_{\mathrm{i}} g_{\mathrm{eff}}^{2}}{a^{2} C_{0}}},
$$

where $D_{\mathrm{i}}$ is the flexural rigidity, $g_{\mathrm{eff}}$ is the effective gap and $C_{0}$ is the capacitance of the unbiased cell. These parameters take all the dimensions of the CMUT cell into account. The center deflection of the plate normalized to the vacuum gap thickness as function of the applied voltage normalized to the pull-in voltage, $V_{\mathrm{pi}}$, is plotted in Fig. 3. The analytic model is compared to a transient and a static PZFlex model. The models are identical, the only difference is the ramp time of the voltage. The transient model is ramped by $270 \mathrm{~V} / \mu$ s whereas each step in the static model is run until steady state. The two models agree with a difference less than $2 \%$ relative to the analytic model. In the transient model, the inertia of the plate is captured, as the plate does not snap in, predicting a $10 \mathrm{~V}$ higher pull-in voltage in this case.

The resonance frequency of the fabricated CMUT array is extracted using an impedance measurement where the resonance peak is tracked for varying bias voltages. To extract the resonance frequency from PZFlex, a single cell CMUT model is used with the same dimensions as the measured. The CMUT cell in vacuum is biased and a static analysis is run to calculate the deflection of the plate. The CMUT is then excited with a wideband $\mathrm{AC}$ voltage on top of the bias in a transient study. The impulse response is calculated by deconvolving the displacement of the center of the plate 


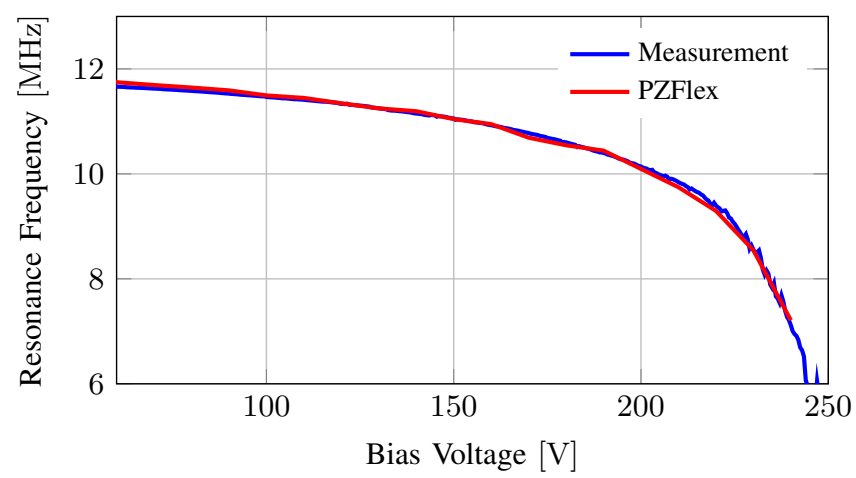

Fig. 4. The resonance frequency of the transient PZFlex model compared to real measurements of a CMUT element for varying bias voltages

with the drive signal. The resonance frequency is found at the maximum value of the frequency spectrum of the impulse response. The resonance frequency of the transient PZFlex model compared to real measurements of a CMUT element is shown in Fig. 4. The model agrees with measurements with a difference of less than $3 \%$.

\section{Acoustics}

After verifying that the electro-mechanical domain calculations work, the acoustic part is now investigated. An array model similar to the CMUT probe described in section II-B is simulated. The model has three cells in each element in the azimuth direction and seven elements in total. A bias voltage of $80 \%$ of the pull-in is used, and the center element is excited with a $1 V_{\text {peak }}$ Blackman-Harris pulse with a center frequency of $8 \mathrm{MHz}$.

From the pressure, extrapolated at a distance of $10 \mathrm{~mm}$, the transmit impulse response is extracted by a deconvolution. This is done by normalizing the extrapolated pressure with the excitation pulse in the frequency domain and applying a window over the region of interest.

The transmit impulse response of the CMUT probe is measured using an AIMS III intensity measurement system (Onda Corp., California, USA) with an Onda HGL-0400 Hydrophone connected to the experimental research ultrasound scanner, SARUS [8]. The method used to measure and calculate the transmit impulse response is described in [9].

The impulse response in the time domain, the envelope and the impulse response in the frequency domain are shown in Fig. 5. All of the three responses are normalized to its maximum value as the amplitude otherwise would not fit. The simulation does not take the elevation focus into account and the extrapolation does not incorporate the symmetry that the simulation does. Otherwise, there is a excellent agreement between the simulation and measured impulse response, but with a slightly higher prediction of the center frequency from the simulation.

\section{IMAGING ASSESSMENT}

Two different transducers are simulated in PZFlex. One with a plate thickness of $2 \mu \mathrm{m}$ and a second with a plate thickness of $10 \mu \mathrm{m}$. Both of them having a center frequency in the $5 \mathrm{MHz}$ range and a pull-in voltage of $200 \mathrm{~V}$. The impulse responses of both transducers are shown in Fig. 6. A higher transmit sensitivity is obtained by increasing the plate thickness from 2 to $10 \mu \mathrm{m}$, but at the expense of the pulse length/bandwidth (as seen in [10]). The peak-peak transmit sensitivity is increased from $25.2 \mathrm{kPa} / \mathrm{V}$ to $75.6 \mathrm{kPa} / \mathrm{V}$, and the bandwidth is decreased from $11.6 \mathrm{MHz}$ to $3.1 \mathrm{MHz}$.

A simulation of 41 point scatterers at depths from $10-50 \mathrm{~mm}$ are performed using the Field II simulation program [11], [12]. Two transducers with 128 elements and a pitch of $200 \mu \mathrm{m}$ are simulated. The imaging sequence consist of line-by-line imaging with 129 focused emissions, 64 active elements, and an $F \#$ of 2 in transmit. The PZFlex simulated transmit impulse responses for the transducers are used in the Field II simulation in the transmit stage, while a standard Hamming weighted 2-cycle sinusoid are used in the receive part. The excitation pulse are a 1-cycle sinusoid at $5 \mathrm{MHz}$. For beamformation, dynamic receive focusing and a receive $f_{\#}$ of 1 are employed.

From the point scatters, the point spread function at varying depth is estimated and from these the imaging quality can be evaluated. Both the lateral and axial resolution is estimated based on the FWHM and the cystic resolution, which is the radius of the $-20 \mathrm{~dB}$ contour line [13]. The resolutions of both transducers are shown in Fig. 7. The lateral resolution is identical for the two transducers, as expected, as it is determined by the transducer layout. The axial resolution is better for the $2 \mu \mathrm{m}$ plate, as it is directly proportional with the pulse length. It is therefore interesting that the $10 \mu \mathrm{m}$ transducer has a slightly better cystic resolution, hence better at suppressing the side-lobes.

\section{CONCLUSION}

This paper demonstrated PZFlex as a modeling tool for simulating CMUT arrays. A 3-D model of a CMUT array was developed with multiple cells in each element and one active element surrounded by $N$ passive elements. It was demonstrated that the electro-mechanics could precisely be predicted within $3 \%$, both the pull-in voltage and the spring softening effect. The transmit impulse response was simulated by deconvolving the extrapolated pressure with the excitation pulse and it was in excellent agreement with the measured. The impulse response could directly be used in Field II to assess the image quality of the transducer using the lateral, axial, and cystic resolution.

\section{ACKNOWLEDGEMENT}

This work is financially supported by the Danish National Advanced Technology Foundation (82-2012-4) and by BK Ultrasound, Herlev, Denmark.

\section{REFERENCES}

[1] B. Bayram, M. Kupnik, G. G. Yaralioglu, Ö. Oralkan, A. S. Ergun, D.-S Lin, S. H. Wong, and B. T. Khuri-Yakub, "Finite element modeling and experimental characterization of crosstalk in 1-D CMUT arrays," IEEE Trans. Ultrason., Ferroelec., Freq. Contr., vol. 54, no. 2, pp. 418-430, 2007. 

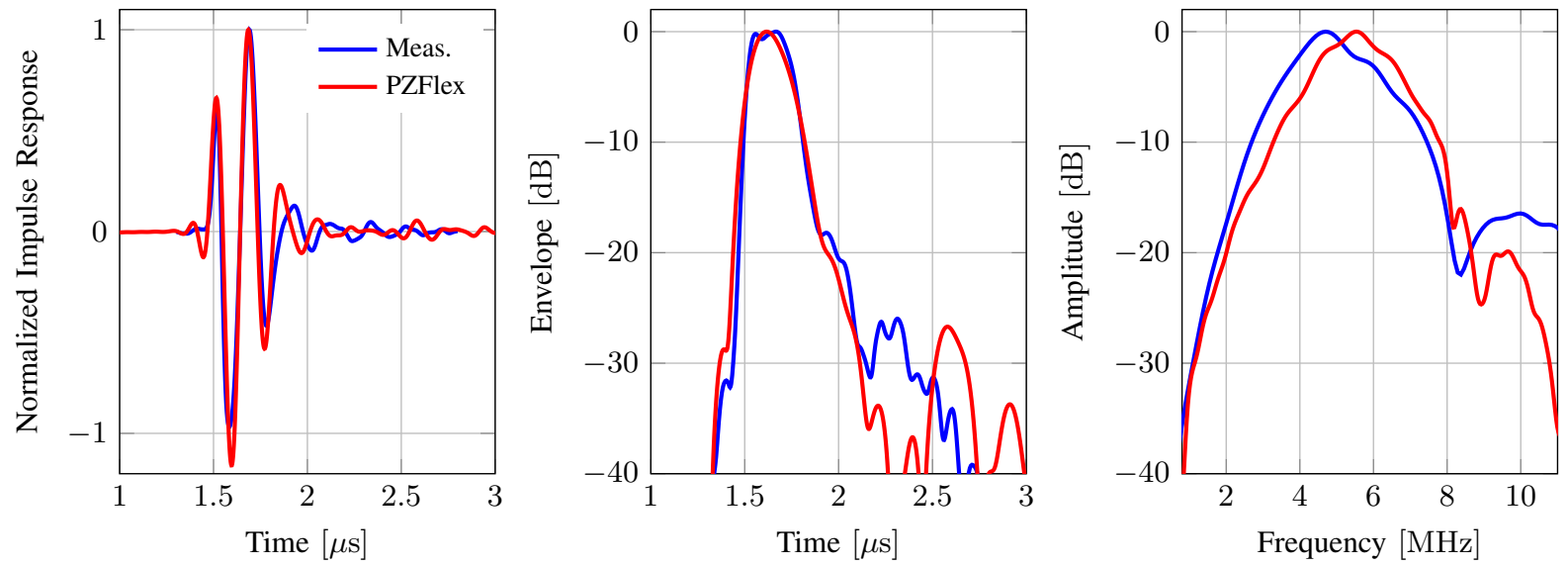

Fig. 5. Transmit impulse response of the PZFlex model compared to measurements. Left: Time domain normalized to maximum positive amplitude. Center: Envelope of the time domain. Right: Frequency domain.
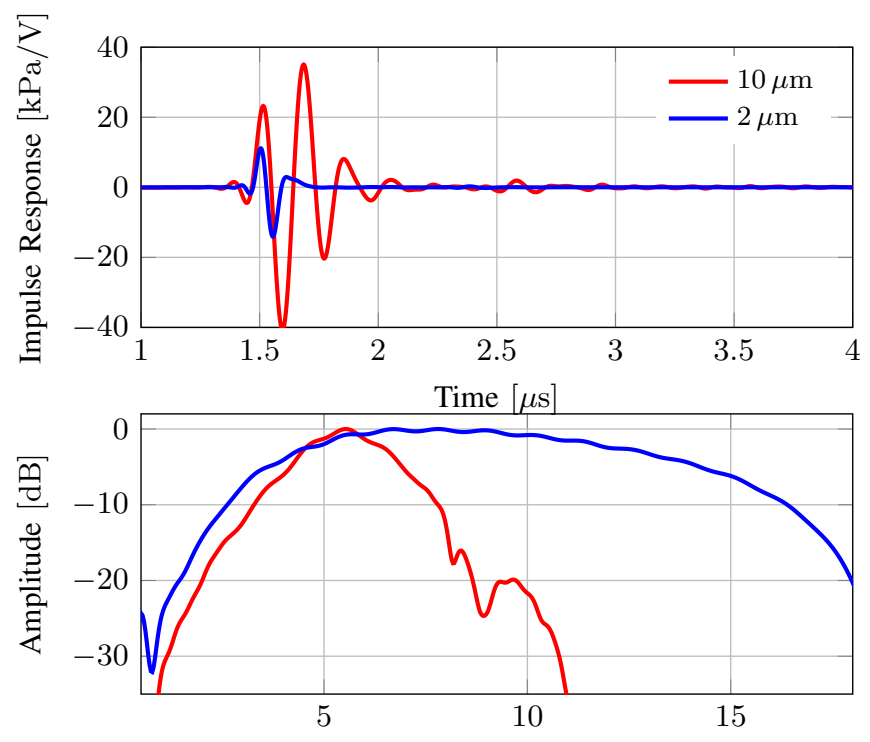

Frequency $[\mathrm{Mhz}]$

Fig. 6. Comparison of the transmit impulse response of two transducers, one with a plate thickness $2 \mu \mathrm{m}$ and a second with a plate thickness of $10 \mu \mathrm{m}$. Top: Time domain. Bottom: Frequency domain.

[2] A. Caronti, G. Caliano, R. Carotenuto, A. Savoia, M. Pappalardo, E. Cianci, and V. Foglietti, "Capacitive micromachined ultrasonic transducer (CMUT) arrays for medical imaging," Microelectronics Journal, vol. 37, no. 8, pp. 770-777, aug 2006.

[3] G. Wojcik, J. Mould, P. Reynolds, A. Fitzgerald, P. Wagner, and I. Ladabaum, "Time-domain models of MUT array cross-talk in silicon substrates," in Proc. IEEE Ultrason. Symp., 2000, pp. 909-914.

[4] Y. Huang, A. S. Ergun, E. Hæggström, M. H. Badi, and B. T. KhuriYakub, "Fabricating capacitive micromachined ultrasonic transducers with wafer-bonding technology," J. Microelectromech. Syst, vol. 12, no. 2, pp. 128-137, 2003.

[5] M. Engholm, T. L. Christiansen, C. Beers, J. P. Bagge, L. N. Moesner, H. Bouzari, A. Lei, M. Berkheimer, M. B. Stuart, J. A. Jensen, and E. V. Thomsen, "A hand-held row-column addressed CMUT probe with integrated electronics for volumetric imaging," in Proc. IEEE Ultrason. Symp., 2015, pp. 1-4.

[6] K. K. Park, H. J. Lee, M. Kupnik, Ö. Oralkan, and B. T. Khuri-Yakub, "Fabricating capacitive micromachined ultrasonic transducers with direct wafer-bonding and locos technology," in IEEE International Conference on Micro Electro Mechanical Systems, 2008, pp. 339-342.

[7] M. F. la Cour, T. L. Christiansen, J. A. Jensen, and E. V. Thomsen, "Electrostatic and small-signal analysis of CMUTs with circular and square anisotropic plates," IEEE Trans. Ultrason., Ferroelec., Freq.

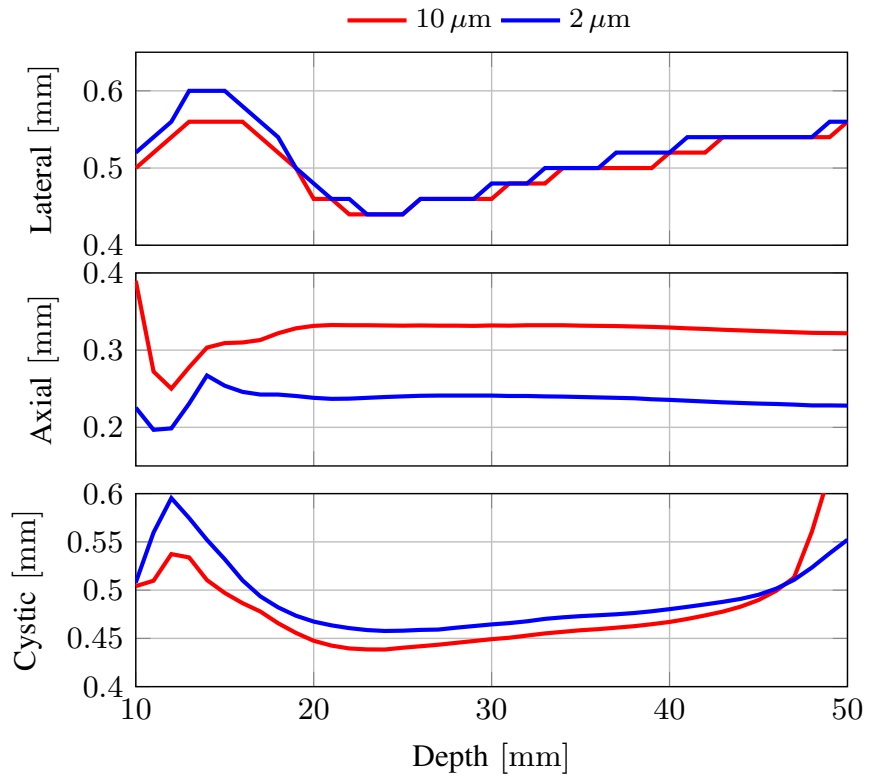

Fig. 7. Assessment of the image quality derived from the point spread function simulated in Field II. Top: Lateral resolution based on FWHM of the PSF. Middle: Axial resolution based on FWHM of the PSF. Bottom: Cystic resolution based on the radius of the $-20 \mathrm{~dB}$ contour line of the PSF

Contr., vol. 62, no. 8, pp. 1563-1579, 2015.

[8] J. A. Jensen, H. Holten-Lund, R. T. Nilsson, M. Hansen, U. D. Larsen, R. P. Domsten, B. G. Tomov, M. B. Stuart, S. I. Nikolov, M. J. Pihl, Y. Du, J. H. Rasmussen, and M. F. Rasmussen, "SARUS: A synthetic aperture real-time ultrasound system," IEEE Trans. Ultrason., Ferroelec., Freq. Contr, vol. 60, no. 9, pp. 1838-1852, 2013.

[9] J. A. Jensen, "Safety assessment of advanced imaging sequences, II: simulations," IEEE Trans. Ultrason., Ferroelec., Freq. Contr., vol. 63, no. 1, pp. 120-127, 2016.

[10] S. E. Diederichsen, J. M. F. Hansen, M. Engholm, J. A. Jensen, and E. V. Thomsen, "Output pressure and pulse-echo characteristics of CMUTs as function of plate dimensions," in Proc. IEEE Ultrason. Symp., 2017, pp. $1-4$.

[11] J. A. Jensen and N. B. Svendsen, "Calculation of pressure fields from arbitrarily shaped, apodized, and excited ultrasound transducers," IEEE Trans. Ultrason., Ferroelec., Freq. Contr., vol. 39, pp. 262-267, 1992.

[12] J. A. Jensen, "Field: A program for simulating ultrasound systems," Med. Biol. Eng. Comp., vol. 10th Nordic-Baltic Conference on Biomedical Imaging, Vol. 4, Supplement 1, Part 1, pp. 351-353, 1996.

[13] K. Ranganathan and W. F. Walker, "Cystic resolution: A performance metric for ultrasound imaging systems," IEEE Trans. Ultrason., Ferroelec., Freq. Contr., vol. 54, no. 4, pp. 782-792, 2007. 